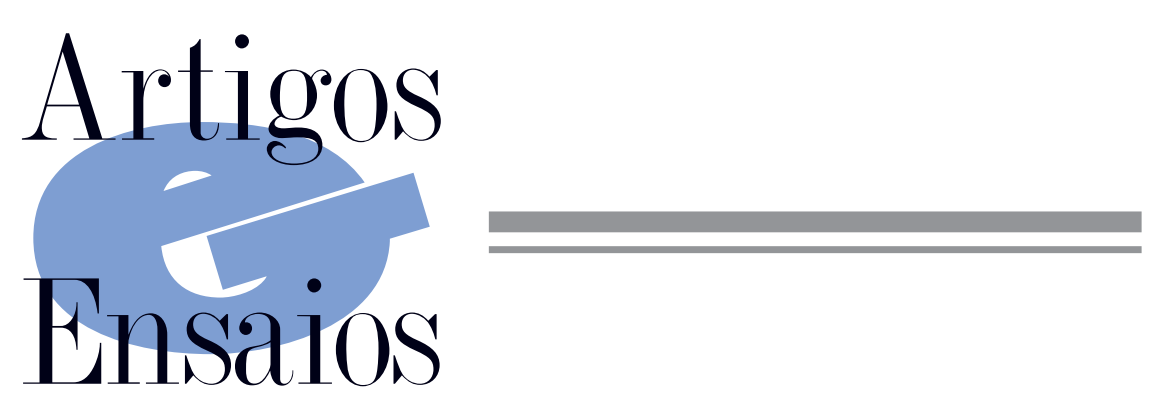

\section{MAPAS E MUSEUS: UMA NOVA CARTOGRAFIA SOCIAL}

\section{Alfredo Wagner Berno de Almeida}

Uma distinção necessária para início de conversa: a proposição de uma "nova cartografia social", enquanto orientadora de práticas de pesquisa, distingue-se do sentido corrente do vocábulo "cartografia" e não pode ser entendida como circunscrevendo-se a uma descrição de cartas ou a um traçado de mapas e seus pontos cardeais com vistas à defesa ou à apropriação de um território. Distingue-se igualmente do sentido manualesco de "cartografia social" que vem sendo largamente usado por agências multilaterais, empresas mineradoras e de georreferenciamento, como a Google. Ao contrário de qualquer significação única, dicionarizada e fechada, a ideia de "nova" visa propiciar uma pluralidade de entradas a uma descrição aberta, conectável em todas as suas dimensões, e voltada para múltiplas experimentações fundadas, sobretudo, num conhecimento mais detido de realidades localizadas. A verificação in loco de situações empiricamente observáveis remete, sobretudo, a relações de pesquisa e de confiança mútua entre os investigadores e os agentes sociais estudados, que se referem aos chamados povos e comunidades tradicionais.

Essa descrição de pretensão plural compreende práticas de trabalho de campo e relações em planos sociais diversos, que envolvem múltiplos agentes, os quais contribuiriam à descrição com suas narrativas míticas, suas sequências cerimoniais, suas modalidades próprias de uso dos recursos naturais e seus atos e modos intrínsecos de percepção de categorias (tempo, espaço, lugar) e objetos. Semelhante construção descritiva, que nada tem de uma interpretação dos atos como texto, ocorre na "confrontação contínua das experiências e das reflexões dos participantes" [1], desfazendo a ilusão empirista das "auto evidências" de campo e a ilusão culturalista que enfatiza a "textualização". As confrontações acham-se dispersas na vida social e se estruturam a partir da perspectiva de diferentes posições e relações sociais e não apenas do prisma das instâncias de poder referidas ao Estado ou do "ponto de vista dos nativos".

Poderia ser nomeada como uma "nova descrição", que se avizinha da etnografia, ao buscar descrever de maneira detida, através de relações de pesquisa e de técnicas de observação direta, a vida social de povos, comunidades e grupos, classificados como "tradicionais" e considerados à margem da cena política, mas que revelam consciência de suas fronteiras e dos meios de descrevê-la, principalmente em situações de conflito social. Está se chamando de consciência de suas fronteiras a confluência de pelo menos duas vertentes, ou seja, a unificação da consciência de seu território com a consciência de si mesmos, manifestas de maneira explícita pelos próprios agentes sociais em suas reivindicações face ao Estado.

Tal unificação indica uma ruptura com o monopólio de classificações identitárias e territoriais produzidas historicamente pela sociedade colonial, mediante recenseamentos, cadastros, inventários, códigos e mapas. Enuncia uma tensão, cada vez mais perceptível, entre a consciência de si mesmos, expressa por ações coletivas, por mobilizações políticas e pelas autodefinições, e as categorias censitárias de identidade, apoiadas em critérios cromáticos (preto, amarelo, branco, pardo) e primordialistas, de nítida inspiração em classificações raciais, impostas uniformemente 


\section{Artigos $\odot$ Ensaios}
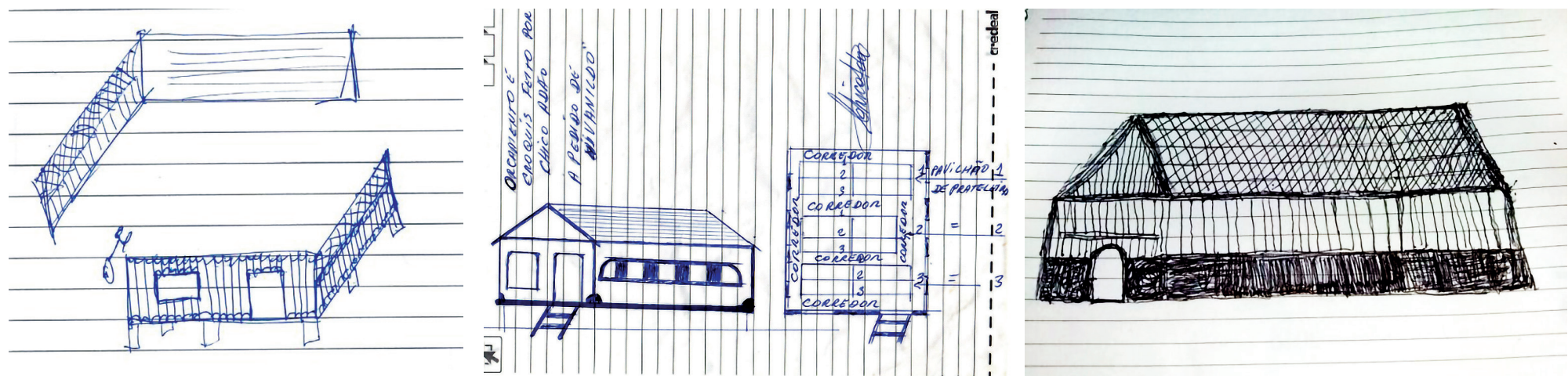

Da esquerda para a direita: figura 1. Croqui Museu Quilombola de Cachoeira Porteira, Pará; figura 2. Croqui do Centro de Ciências e Saberes da Comunidade Remanescente de Quilombo do Jauari - Rio Erepecuru, Oriximiná, Pará; figura 3. Croqui do Museu das Comunidades Quilombolas de Barreirinha, Amazonas

pelo poder do Estado desde pelo menos 1872, data do primeiro censo demográfico do Brasil.

A principal configuração dessa ruptura concerne a um quadro de intensas mobilizações políticas desses agentes sociais articuladas tanto com o advento das categorias de autodefinição, quanto com a emergência de formas político-organizativas específicas. Ambas convergem para uma identidade coletiva objetivada em movimento social, notadamente a partir de 1985-86, no âmbito das discussões que perpassaram a Constituinte e foram incorporadas à Constituição Federal de 1988. Por meio dessas práticas mobilizatórias, que evidenciam conhecimento de seus direitos constitucionais, é que tais agentes interrogam sobre suas relações com a política, parcialmente exprimidas pelas organizações e movimentos que os representam.

Entre 2005 e 2018, na execução de atividades de mapeamento social, verificamos o surgimento dos chamados "museus vivos" ou "pequenos museus" em territórios étnicos, em povoados, em projetos de assentamento e em bairros periféricos das metrópoles. A primeira constatação é que, tal como os mapas, esses "pequenos museus" são acionados hoje nas mobilizações pelo reconhecimento identitário de povos e comunidades tradicionais, tornando-se um fator dinâmico de conhecimentos específicos e um instrumento político. Também de forma semelhante ao que acontece com os mapas, verifica-se que a ideia de museu está sendo apropriada por aqueles que são usualmente designados como os "outros". Em outras palavras, o mapa nos levou ao museu. A "nova cartografia" nos impeliu aos novos significados de museu vivo, que passam a integrar seu campo de significação. Os croquis e mapas são complementados com a consolidação de museus vivos, cujas plantas são produzidas pelos próprios membros das comunidades tradicionais, tal como o mapeamento social. Os chamados "outros" se tornam autores e sujeitos da ação que consolida seus territórios, como veremos adiante.

O pano de fundo concerne às vicissitudes de processos reais e de realidades empiricamente observáveis no decorrer dos trabalhos de campo realizados em regiões amazônicas pelos pesquisadores do Programa de Pós-Graduação em Cartografia Social e Política da Amazônia (PNCSA) da Universidade Estadual do Maranhão (Uema), que já realizaram nos últimos 13 anos quase três centenas de mapeamentos, publicados em fascículos e disponibilizados no site www.novacartgografiasocial.com, e já contribuíram na montagem de cerca de 20 museus vivos ou pequenos museus. Dentre eles gostaríamos de destacar aqueles apoiados pela rede de pesquisadores da Nova Cartografia Social, consolidados através do projeto "Centro de ciências e saberes (CCS): experiência de criação de museus vivos na afirmação de saberes e fazeres representativos dos povos e comunidades tradicionais" (MCTI/CNPq/SECIS N.85/2013. Projeto N.458207/2013-6), quais sejam: CCS Mãe Anica, em Canelatiua (Alcântara, MA); CCS Lua Verde e CCS Antonio Samias, ambos dos Kokama, em Manaus (AM); CCS do Povo Tremembé, na Raposa (MA); CCS das Comunidades Quilombolas do Andirá (AM); CCS Museu Casa Branca, em Imperatriz (MA); e CCS Escola da Cultura, em São José da Povoação (Curralinho, PA). Ainda, os CCS's em consolidação na comunidade quilombola de Cachoeira Porteira, no 


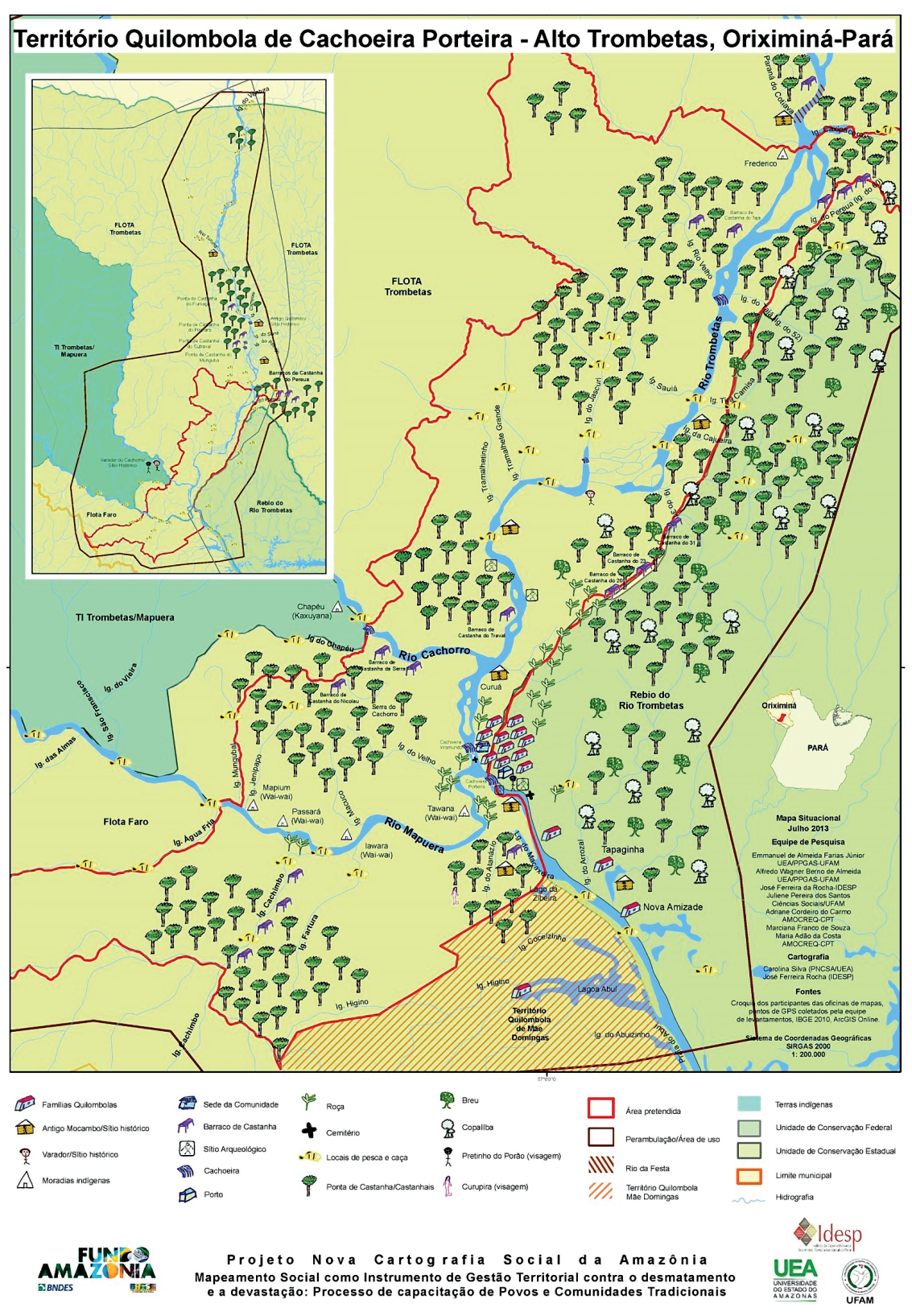

Mapa do território quilombola de Cachoeira Porteira, Alto Trombetas, Oriximiná, Pará drões culturais, e o empenho em produzir seus próprios mapas demonstram não apenas uma afirmação identitária, mas sobretudo situações de tensão social, envolvendo povos e comunidades tradicionais, cujos territórios e bens culturais encontram-se submetidos a grandes riscos, ameaçados por conflitos provocados pela implantação de megaempreendimentos e obras de infraestrutura e de segurança. Barragens, bases de lançamento de foguetes, ferrovias, rodovias, portos, minerodutos, gasodutos, oleodutos, linhas de transmissão de energia e hidrovias, implantados de maneira concomitante, provocam danos e têm efeitos devastadores sobre o modo de vida e a reprodução desses povos e comunidades e sobre o que eles consideram os lugares relevantes de sua memória histórica. Insisto, pois, na pergunta: como interpretar a atual disseminação dessas iniciativas de "museus vivos" e demais práticas designadas através de expressões similares em que o termo "museu" funciona como uma sorte de prefixo, acompanhado da identidade social respectiva e suas variantes, tais como: museu indígena (Kokama, Tremembé, Ticuna), museu quilombola, museu de quebradeiras de coco babaçu, museu de ribeirinhos, museu de seringueiros, museu de castanheiros, museu de pantaneiros, museu de pescadores artesanais, museu de piaçabeiros, museu de caiçaras, museu de geraizeiros, museu das comunidades de fundos e fechos de pasto e museu de faxinais? Antes de tudo, cabe dizer que a nomeação explícita dos rio Trombetas (PA), e na comunidade de ribeirinhos do rio Jauaperi, na Resex do Baixo Rio Branco (RR/AM). Em todas essas situações, as oficinas de mapas nos levaram aos pequenos museus, ou seja, o mapa foi coetâneo do museu [2]. Mas por que tantas comunidades tradicionais demandam mapeamento social e se empenham na montagem de pequenos museus? Os deslocamentos nos significados de museus, ao produzirem coleções intrínsecas aos seus pa- sujeitos na criação desses museus vivos implode com o significado de "outros", evidenciando que, ao omitir ou ocultar deliberadamente o nome, sob uma designação genérica, inviabilizava-se qualquer possibilidade concreta de autodefinição. Ao contrário, no momento atual, as autodefinições é que nomeiam os museus, os territórios e os mapas, demonstrando não somente suas especificidades, mas também que os "museus vivos" são indissociáveis da 


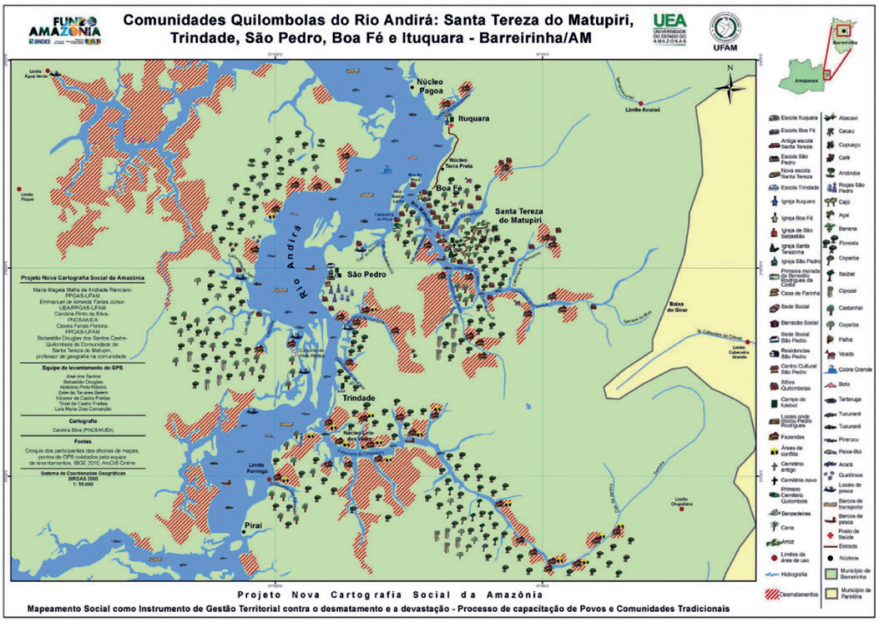

Mapa das comunidades quilombolas do rio Andirá: Santa Tereza do Matupiri, Trindade, São Pedro, Boa Fé e Ituquara-Barreirinha, Amazonas

consciência de si mesmos ou do processo de autodefinição dos agentes sociais correspondentes às identidades coletivas explicitamente mencionadas.

A emergência desses pequenos museus que, inclusive, não demandam necessariamente uma institucionalização, pode ser articulada com a perda da estabilidade semântica de termos e conceitos como "tradição", "exposição" e "coleção" e a complexidade de seus usos sociais na vida cotidiana e em mobilizações políticas por afirmação identitária e por direitos territoriais. Elas colocam na ordem do dia da vida intelectual e política e nos meandros dos mecanismos burocráticos o propósito de repensar os significados usuais de museu e suas variações. Essa tarefa não é trivial, tampouco fácil, uma vez que tais significados, além de historicamente cristalizados, possuem uma ambiguidade conflitiva e deveras perturbadora.

Esse trabalho encerra, pois, uma crítica às noções usuais de cartografia e de historicidade da morte. Os outrora mapeados nos levaram àqueles cujos artefatos eram museificados, como eles próprios, num lento extermínio simbólico. Os museus consistiam nessa paradoxal historicidade da morte, e esse significado de museificação nos remete diretamente a Baudrillard [3]. Por outro lado, as recentes práticas de mapeamento social [4] correspondentes à nova cartografia social nos facultaram condições de possibilidades para detectar o estado nascente de "pequenos museus" ou "museus vivos" e o potencial de mobilização política de povos que reverteram a sua propalada condenação ao extermínio e romperam com os estigmas de "primitivos" e "atrasados", atribuídos usualmente à categoria "outros".

A recorrência com queesses agentes sociais designamsuas iniciativas museológicas como "museus vivos" possibilita a compreensão de porquê atribuem uma ênfase desmedida à vida, desdizendo os "históricos" prognósticos de morte. Ambos, mapa e museu, são coetâneos da emergência dessas identidades coletivas objetivadas em diferentes formas político-organizativas e suas ações transformadoras, que passam a representar a historicidade da vida se contrapondo ao mofo dos museus reais e imperiais, à soturnidade dos museus nacionais e à morte que paira sobre esses grandes museus das antigas metrópoles, que agora buscam desesperadamente se renovar.

Alfredo Wagner Berno de Almeida é antropólogo, professor do Programa de Pós-Graduação em Cartografia Social e Política da Amazônia, da Universidade Estadual do Maranhão (Uema), dos Programas de Pós-Graduação em Cidadania e Direitos Humanos em Segurança Pública e em Ciências Humanas, na Universidade do Estado do Amazonas (UEA), e dos Programas de Pós-Graduação em Sociedade e Cultura na Amazônia e em Antropologia Social, na Universidade Federal do Amazonas (Ufam). É também pesquisador do CNPq.

\section{NOTAS}

1. Bourdieu, P. A miséria do mundo, Petrópolis, Ed. Vozes, 2003.

2. Para maiores informaçôes consulte-se Almeida, A.W.B. de; Arenillas-Oliveira, M. Museus indígenas e quilombolas: Centro de Ciências e Saberes, Manaus, UEA/ MAST/UEMA, 2018.

3. O conceito de museificação, como historicidade da morte, é trabalhado por Baudrillard, in Simulacros e simulação, em consonância, a nosso ver, com Sartre e Merleau-Ponty, senão vejamos: "Estamos fascinados com Ramsés como os cristãos da Renascença o estavam com os índios da América, que nunca tinham conhecido a palavra de Cristo (...). Deste modo terá bastado exumar Ramsés para o exterminar ao museificar: é que as múmias não apodrecem com os vermes: elas morrem por transumarem de uma ordem lenta do simbólico, senhora da podridão e da morte, para uma ordem da história, da ciência e do museu, a nossa, que já não domina nada, que só sabe votar o que precedeu à podridão e à morte e tentar em seguida ressuscitá-lo pela ciência. Violência irreparável para com todos os segredos, violência de uma civilização sem segredo, ódio de toda uma civilização contra suas próprias bases.”. Ver Baudrillard, J. Simulacros e simulação, Portugal, Relógio d'Agua, 1991.

4. Referência ao Projeto Nova Cartografia Social da Amazônia (PNCSA), instituído a partir de 2005 por uma rede de pesquisadores de universidades públicas da Amazônia e do Nordeste. 